\title{
Electroinitiated polymerization of MDI (methylene 4,4'-diphenyl diisocyanate) with polyoxy propyleneglycol polyurethane synthesis
}

\author{
P A K NEDUNGADI, T KUNJU, K KUMAR, SANJAY MATHUR, \\ $T$ PETER, A DHAS and K ZUTSHI* \\ Department of Chemistry, University of Rajasthan, Jaipur 302 004, India \\ MS received 11 December 1989; revised 2 May 1991
}

\begin{abstract}
Electroinitiated polymerization of urethane was carried out using electrolysis of MDI (methylene 4,4'-diphenyl diisocyanate) with polyoxypropylene glycol in dimethyl sulphoxide (DMSO) and dimethylformamide (DMF) in the presence of oxides and chlorides of $\mathrm{Zn}, \mathrm{Cd}, \mathrm{Pb}$ and $\mathrm{Sn}$ as supporting electrolytes. These salts also served as complexing agents. The polymer formation took place only in the cathodic compartment having good yields with highest $R_{p}$ of $16.25 \%$ per $\mathrm{h}$ and polymerization efficiency of $30 \times 10^{2}$ moles of monomer converted per Faraday in DMF solvent. The mechanism of polymerization has been suggested.
\end{abstract}

Keywords. Electroinitiated polymerization; methylene-diphenyl diisocyanate; polyoxy propyleneglycol; polyurethane synthesis.

\section{Introduction}

There has been a great deal of interest in the synthesis and properties of conventional urethanes and their microphase structure, which was responsible for increasing material strength (Estes et al 1970; Noshay and Mc Grath 1973; Gibson et al 1982). Polyurethane coatings were first developed by Bayer and his coworkers (Dietrich et al 1962) and significant progress has been made in this area due to the wide latitude of physical properties ranging from very flexible to hard materials. These copolymers were also used as fibres, elastomers and foams.

The present study reports electroinitiated polymerization by condensing methylene, 4, 4' -diphenyl diisocyanate (MDI) with polyoxypropylene glycol (polyol) in a single phase (DMSO or DMF) in the presence of supporting electrolytes (chlorides and oxides of $\mathrm{Zn}, \mathrm{Cd}, \mathrm{Pb}$ and $\mathrm{Cu}$ ). These salts were used to view their efficiency in promoting electropolymerization in terms of donor-acceptor complexing property.

Polyurethanes were formed by either of the two methods: (i) by interfacial polycondensation or (ii) by low temperature solution polycondensation on gently mixing the diisocyanate with the polyol and subsequently passing current where additional polymerization sets in. In bulk polymerization, dropwise controlled addition of diisocyanate to a magnetically stirred dry and pure glycol was done. This rendered a smooth reaction and maintained a steady temperature as far as practicable. Intermittent cooling was necessary to avoid excess of heat liberated $(224 \mathrm{~kJ} / \mathrm{mol})$ by the formation of urethane during reaction. There was a distinct disadvantage in this process in that the polyurethane once formed was always prone to attack by diisocyanate throughout the reaction. Consequently secondary reactions were found to take place. In solution polymerization, however, all these difficulties were overcome and the polymer film obtained was with a fine structure 
and high molecular weight and therefore it was adopted by us. It was observed that rapid mixing facilitated rapid precipitation of the polymer. The acid compounds inhibited the process while the basic ones, metal salts and organometallics accelerate them. A proper choice of reaction conditions and solvent was necessary for this synthesis. Literature (Gaylor and Takahashi 1969; Funt et al 1970; Funt and Rybicky 1971) cite the usefulness of donor-acceptor complex arising from a combination between zinc salts and monomer in initiating the polymerization. Since supporting electrolytes were highly ionic in character, the solvents with high dielectric constant DMSO and DMF were used. This facilitated easy dissolution of polymers formed and also the supporting electrolytes.

\section{Experimental}

\subsection{Materials}

DMSO was purified (Kolthoff and Redly 1961) by suspending it overnight over heated alumina, as also by partial freezing, decanting the liquid and azeotropically distillating with $50 \mathrm{ml}$ benzene per litre. Metal salts used were all from Aldrich chemicals, DMF (Aldrich) and MDI (BASF) and were of AnalaR grade.

NMR spectra were recorded on a Perkin-Elmer R-12B $60 \mathrm{MHz}$ spectrometer in DMSO-d ${ }_{6}$ using TMS as internal standard.

\subsection{Cell assembly}

Al sheets (working area $1 \mathrm{~cm}^{2}$ ) were used as electrodes in a $\mathrm{H}$-shaped glass cell for electropolymerization. For current-potential measurements a two-electrode system was used. The current was measured from a sensitive milliameter (Simpson) and the potential from a high impedance voltameter. Polarization was studied with respect to SCE at $30-35^{\circ} \mathrm{C}$.

\subsection{Electrolysis and workup}

Electrolysis was carried out by varying the following parameters: (i) supporting electrolytes, (ii) current, (iii) concentration of monomers (MDI) and (iv) solvent. Controlled electrolysis was done with a regulated DC power supply, capable of giving $0-5 \mathrm{~A}$ at $0-50 \mathrm{~V}$. The yield of polymer at certain interval of time of electrolysis was determined by the terminating electrolysis, precipitating the whole of catholyte with acidified methanol, and drying the polymer in an air oven at $100^{\circ} \mathrm{C}$.

The viscosity molecular weight was determined by taking the polymer in DMF and using the relation (Goldberg et al 1967) $M_{V}=\operatorname{antilog} \frac{1}{a}(\log n / k ; a=0.67, k$ Huggins constant $\left(5 \times 10^{-4}\right) ; \eta=$ intrinsic viscosity and $\eta$ varied from 0.98 to 1.25 .

\subsection{General experimental procedure}

Polyol $(1.0 \mathrm{~mol})$ was placed in a $\mathrm{H}$-shaped cell containing DMF or DMSO $(25 \mathrm{ml})$ 


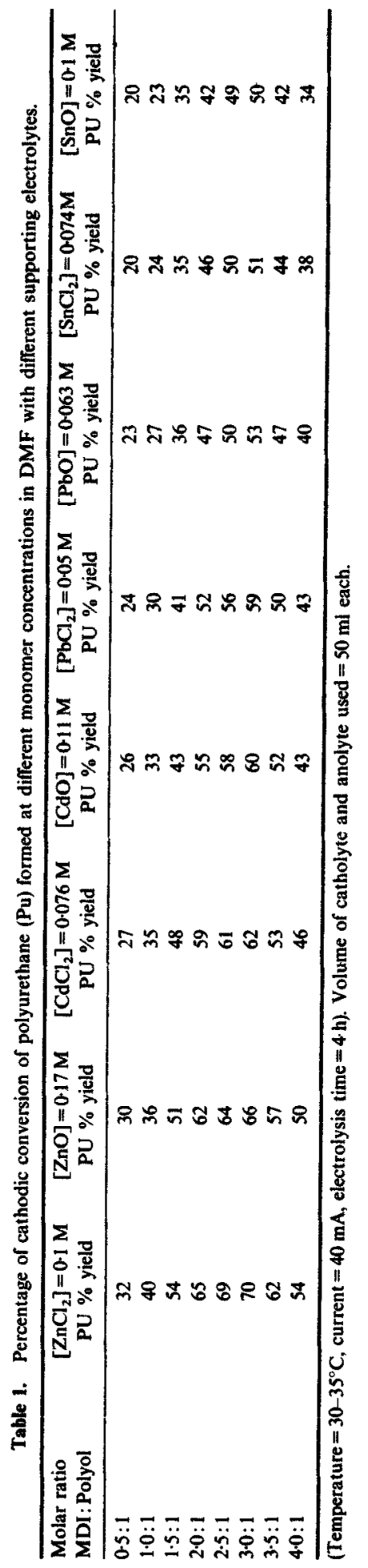


and $\mathrm{Al}$ electrodes (working area $10 \mathrm{~cm}^{2}$ ) suspended in it. To it was added the electrolyte, oxide or chloride of $\mathrm{Zn}, \mathrm{Cd}, \mathrm{Pb}$ or $\mathrm{Sn}$ in the range varying from 0.05 to $0.10 \mathrm{~mol} / \mathrm{l}$. Carefully controlled addition of MDI $(2.0 \mathrm{~mol})$ was done under magnetic stirring and current passed for $4 \mathrm{~h}$ at $30-35^{\circ} \mathrm{C}$. The polymer was precipitated with acidified methanol and recovered in cathodic compartment only. The polyurethane obtained was characterized by ${ }^{1} \mathrm{H}-\mathrm{NMR}$ spectra in DMSO- $\mathrm{d}_{6}$. The ${ }^{1} \mathrm{H}$ NMR was very simple and showed peaks at (i) $0.76 \mathrm{ppm}$ characteristic of $\mathrm{CH}_{3}$ group, (ii) 1.52 ppm corresponding to the $-\mathrm{CH}_{2}$ group, (iii) $1.8 \mathrm{ppm}$ signifying $-\mathrm{CH}$ group, (iv) a multiplet at $6.44 \mathrm{ppm}$ attributing to benzene nucleus and (v) a singlet at $8.88 \mathrm{ppm}$ corresponding to $-\mathrm{NH}$ group. The $\mathrm{CH}_{3}$ of DMSO-d ${ }_{6}$ emerged at $2.52 \mathrm{ppm}$.

\section{Results and discussions}

\subsection{Effect of monomer concentration, supporting electrolytes and solvents}

When the mixture of MDI and polyol was kept at room temperature for several days, no polymerization took place. The rate of polymer formation varied linearly with monomer concentration up to an MDI: polyol ratio of $2: 1$ but beyond this ratio the percentage of conversion slowly decreased. Beyond a MDI: polyol ratio of $2 \cdot 5: 1$, evolution of $\mathrm{CO}_{2}$ took place which again suggested side reactions taking place. The results in DMF are summarized in table 1.

The results of electropolymerization of MDI with polyol in DMF and DMSO, listed in tables 2 and 3, indicate that DMF was a better solvent for the synthesis of polyurethane as compared to DMSO which meant that the yield of polyurethane increased as the solvent became more and more neutral in character. From the tables it is also evident that zinc chloride resulted in the highest percentage yield of polyurethane in both the solvents. The activity of supporting electrolytes was in the order $\mathrm{Zn}>\mathrm{Cd}>\mathrm{Pb}>\mathrm{Sn}$. The polymer formation took place only in cathodic compartment, i.e. nearly no polymer formation took place in the anodic compartment even when the polarity of electrodes was changed every half an hour

Table 2. Electrochemical synthesis of MDI-based polyurethane in DMF.

\begin{tabular}{|c|c|c|c|}
\hline $\begin{array}{l}\text { Electrolyte } \\
\text { (in } \mathrm{mol} / \mathrm{l} \text { ) }\end{array}$ & $\begin{array}{c}\text { Cathodic } \\
\text { conversion }(\%)\end{array}$ & $\begin{array}{c}\text { Rate of } \\
\text { polymerization } \\
\left(R_{p}=\% / \mathrm{h}\right)\end{array}$ & $\begin{array}{c}\text { Polymerization } \\
\text { efficiency = mol } \\
\text { of monomer } \\
\text { converted } \\
\text { per Faraday }\end{array}$ \\
\hline $\mathrm{ZnCl}_{2}=0.1$ & 65 & $16 \cdot 25$ & 30 \\
\hline $\mathrm{ZnO}=0.17$ & 62 & $15 \cdot 50$ & 29 \\
\hline $\mathrm{CdCl}_{2}=0.076$ & 59 & $14 \cdot 75$ & 27 \\
\hline $\mathrm{CdO}=0.11$ & 55 & $13 \cdot 75$ & 25 \\
\hline $\mathrm{PbCl}_{2}=0.05$ & 52 & $13-00$ & 24 \\
\hline $\mathrm{PbO}=0.063$ & 47 & $11 \cdot 75$ & 22 \\
\hline $\mathrm{SnCl}_{2}=0.074$ & 46 & $11 \cdot 50$ & 21 \\
\hline $\mathrm{SnO}=0 \cdot 1$ & 42 & $10 \cdot 50$ & 19 \\
\hline
\end{tabular}

(Current $=40 \mathrm{~mA} ;$ temperature $=30-35^{\circ} \mathrm{C} ;$ molar ratio of $\mathrm{MDI}:$ Polyol $=2: 1$ and electrolysis time $=4 \mathrm{~h}$ ). Volume of catholyte and anolyte used $=50 \mathrm{ml}$ each.

Note: All calculations are done with respect to concentration of MDI. 
Table 3. Electrochemical synthesis of $\mathrm{MDI}=$ based polyurethane in DMSO.

\begin{tabular}{|c|c|c|c|}
\hline $\begin{array}{l}\text { Electrolyte } \\
\text { (in mol/l) }\end{array}$ & $\begin{array}{c}\text { Cathòdic } \\
\text { conversion } \\
(\%)\end{array}$ & $\begin{array}{c}\text { Rate of } \\
\text { polymerization } \\
\left(R_{p}=\% / h\right)\end{array}$ & $\begin{array}{c}\text { Polymerization } \\
\text { efficiency }= \\
\text { moles of monomer } \\
\text { converted per Faraday }\end{array}$ \\
\hline $\mathrm{ZnCl}_{2}=0.1$ & 60 & 15.00 & 28 \\
\hline $\mathrm{ZnO}=0.17$ & 58 & $14 \cdot 50$ & 27 \\
\hline $\mathrm{CdCl}_{2}=0.076$ & 55 & $13 \cdot 75$ & 25 \\
\hline $\mathrm{CdO}=0.11$ & 51 & $12 \cdot 75$ & 23 \\
\hline $\mathrm{PbCl}_{2}=0.05$ & 52 & 13.00 & 24 \\
\hline $\mathrm{PbO}=0.063$ & 45 & $11 \cdot 25$ & 21 \\
\hline $\mathrm{SnCl}_{2}=0.074$ & 43 & $10 \cdot 75$ & 20 \\
\hline $\mathrm{SnO}=0.1$ & 38 & $9 \cdot 50$ & 18 \\
\hline
\end{tabular}

(Current $=40 \mathrm{~mA}$; temperature $=30-35^{\circ} \mathrm{C} ;$ molar ratio of $\mathrm{MDI}:$ polyol $=2: 1$ and electrolysis time $=4 \mathrm{~h}$ ). Volume of catholyte and anolyte used $=50 \mathrm{ml}$ each.

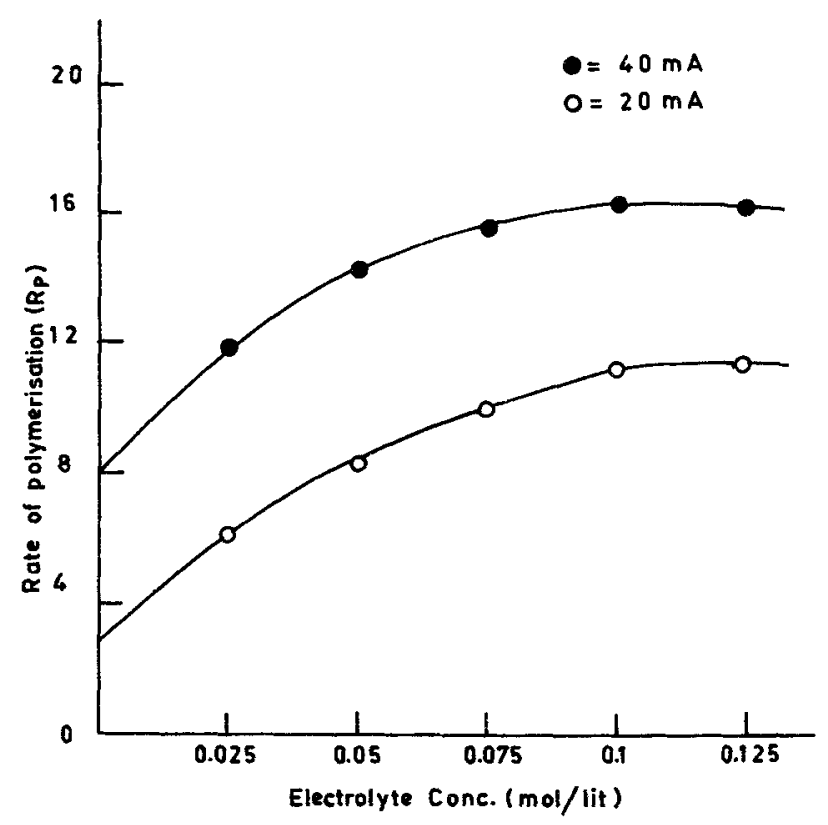

Figure 1. Rate of polymerization plotted against electrolyte concentration $\left(\mathrm{ZnCl}_{2}\right)$ in DMF : molar ratio of $\mathrm{MDI}:$ polyol $=2: 1$; temperature $=30-35^{\circ} \mathrm{C}$; electrolysis time $=4 \mathrm{~h}$; volume of catholyte and anolyte used $=50 \mathrm{ml}$ each.

to present electrode surface from getting heavy metallic depositions. The rate of polymerization was also dependent upon the electrolyte concentration but at very high concentration ( $\geq 0 \cdot 15 \mathrm{~mol} / 1)$, it touched a constant value. This is depicted in figure 1 .

\subsection{Current variation}

Figure 2 shows the curve for cathodic conversion with $\mathrm{ZnCl}_{2}$ at different currents 


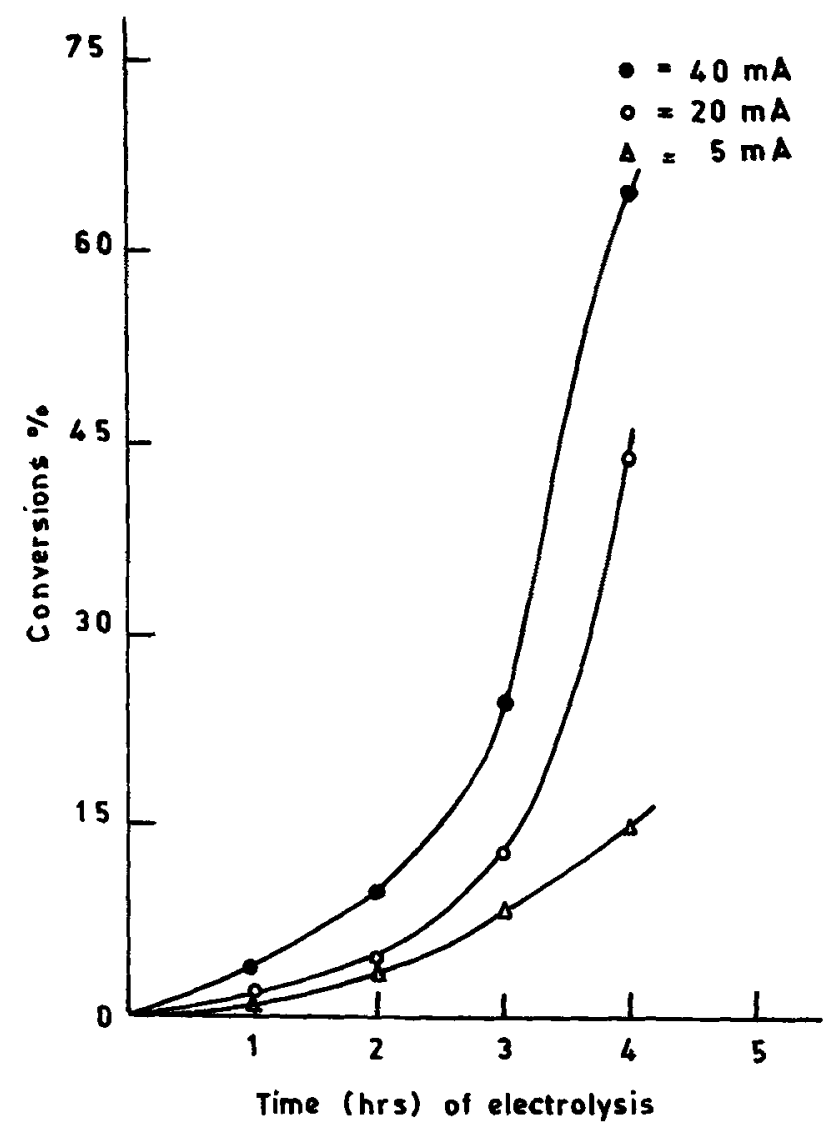

Figure 2. Percentage of conversion plotted against time of electrolysis for electrochemical syntheşis of polyurethane. Temperature $=30-35^{\circ} \mathrm{C} ;\left(\mathrm{ZnCl}_{2}\right)=0.1 \mathrm{M}$, solvent $=\mathrm{DMF}:$ molar ratio of $\mathrm{MDI}$ : polyol $=2: 1$. Volume of catholyte used $=50 \mathrm{ml}$ each.

(20, 30 and $40 \mathrm{~mA}$ ). Cathode was found to be heavily coated with the polymer and zinc metal. At the initial stages of induction period, the percentage of conversion was very low and increased linearly with time. Also, a similar trend was observed with the amount of current passed but attained constancy after a certain amount of current was passed (figure 3).

\subsection{Post and pre-electrolytic behaviour and reaction mechanism}

2:1 MDI + polyol mixture was added to a preelectrolysed solution of $0 \cdot 1 \mathrm{M}$ zinc chloride (Parravano 1951; Kern and Quast 1953). Polymerization took place both in cathodic and anodic compartments but the conversion obtained with the polymerization time of $33-35 \mathrm{~h}$ was a meagre $4 \%$. This is depicted in table 4 .

The polymer formation continued even after the termination of passage of electricity in cathodic compartment. This is shown in figure 4. A conversion of $9 \%$ evident in the figure was obtained in almost an hour which was attributed to low termination rates. 


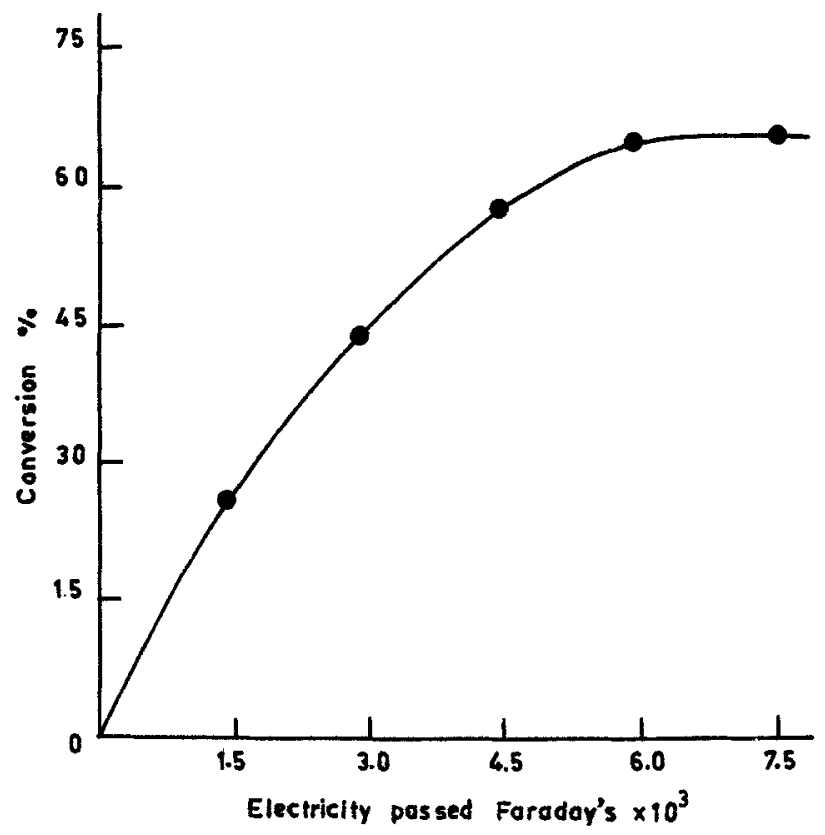

Figure 3. Percentage of conversion plotted against different current strengths for electrochemical synthesis of polyurethane in DMF. Molar ratio of MDI: polyol =2:1; temperature $=30-35^{\circ} \mathrm{C}$; supporting electrolyte $=0.1 \mathrm{M} \mathrm{ZnCl}$; electrolysis time $=4 \mathrm{~h}$. Volume of catholyte and anolyte used $=50 \mathrm{ml} \mathrm{each}$.

Table 4. Pre-electrolysis: electrochemical synthesis of polyurethane.

\begin{tabular}{|c|c|c|c|c|c|}
\hline \multirow{2}{*}{$\begin{array}{l}\text { Time of } \mathrm{MDI}+\text { polyol } \\
\text { mixture addition }\end{array}$} & \multirow{2}{*}{$\begin{array}{l}\text { Polymerization } \\
\text { time (h) }\end{array}$} & \multicolumn{2}{|c|}{ DMF } & \multicolumn{2}{|c|}{ DMSO } \\
\hline & & Catholyte & Anolyte & Catholyte & Anolyte \\
\hline Just after electrolysis & 4 & 3.6 & $3 \cdot 6$ & $2 \cdot 7$ & $2 \cdot 7$ \\
\hline $1 \mathrm{~h}$ after electrolysis & $8-10$ & $1 \cdot 2$ & $1 \cdot 2$ & 0.5 & 0.5 \\
\hline $2 \mathrm{~h}$ after electrolysis & $15-18$ & Nil & Nil & Nil & Nil \\
\hline $5 \mathrm{~h}$ after electrolysis & $22-25$ & Nil & Nil & Nil & Nil \\
\hline $10 \mathrm{~h}$ after electrolysis & $27-30$ & $\mathrm{Nil}$ & $\mathrm{Nil}$ & Nil & Nil \\
\hline Just after electrolysis & $33-35$ & 4 & 4 & $3 \cdot 2$ & $3 \cdot 2$ \\
\hline
\end{tabular}

Supporting electrolyte $=0.1 \mathrm{ZnCl}_{2} ;$ molar ratio of $\mathrm{MDI}:$ polyol $=2: 1$; temperature $=30-35^{\circ} \mathrm{C}$; current passed before adding MDI + polyol mixture $=40 \mathrm{~mA}$; volume of catholyte and anolyte $=50 \mathrm{ml}$.

An insight into the reaction mechanism was gained by studying the polarization curves (cathodic and anodic) for $\mathrm{ZnCl}_{2}$ acting as supporting electrolyte in DMF. Figure 5 showing a curve of cathodic potential for $\mathrm{ZnCl}_{2}$ is more negative than that of the 2:1 mixture of MDI: polyol leading to the conclusion that the reverse reaction $\mathrm{Zn}^{2+}+2 \mathrm{e} \rightleftharpoons \mathrm{Zn}$ was prolonged and took place at a higher potential. In the anodic compartment (figure 6) $\mathrm{Cl}_{2}$ gas evolution took place predominantly which was incapable of initiating the polymerization.

Thus, from these experimental observation and polymerization curves, a donoracceptor complex was expected to be formed between metal and the monomer. A ternary complex was thought to be formed (by simple bridging) involving loose 


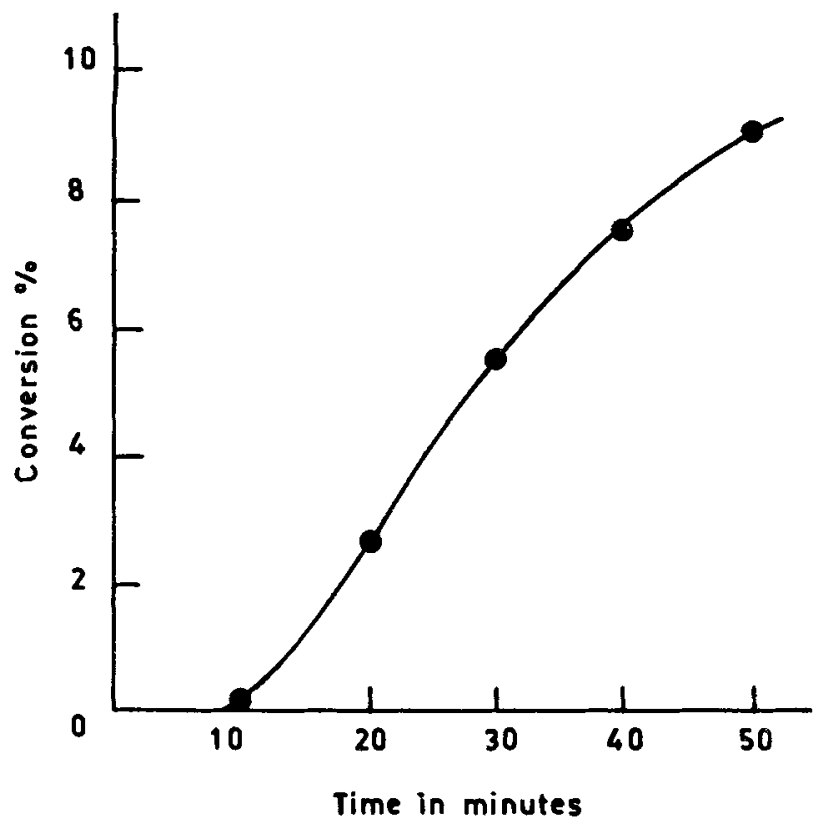

Figure 4. Post polymerization, electrochemical synthesis of polyurethane in DMF. Temperature $=30-35^{\circ} \mathrm{C}$; current $=40 \cdot \mathrm{mA}, \quad\left(\mathrm{ZnCl}_{2}\right)=0.1 \mathrm{M}$; Molar ratio of MDI: polyol $=2 \cdot 1$, volume of catholyte and anolyte used $=50 \mathrm{ml}$ each.

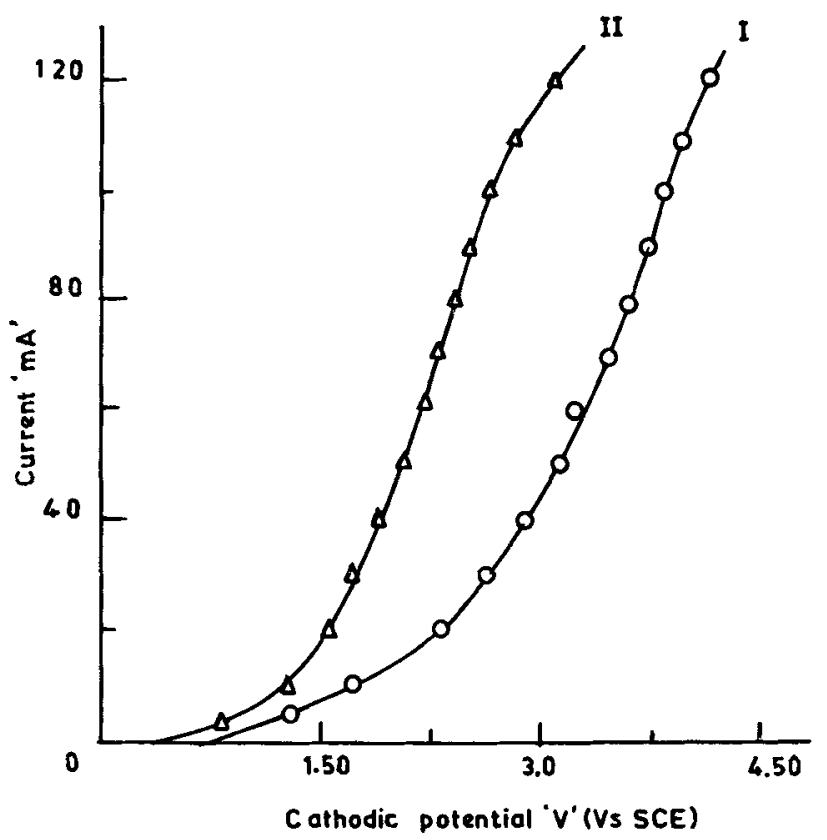

Figure 5. Cathode potential vs current curve for electrochemical synthesis of polyurethane in DMF. Temperature $=30-35 \mathrm{C},\left(\mathrm{ZnCl}_{2}\right)=0.1 \mathrm{M}$. (I) without $\mathrm{MDI}+$ polyol mixture; (II) with $2: 1$ molar ratio of $\mathrm{MDI}$ : polyol. 


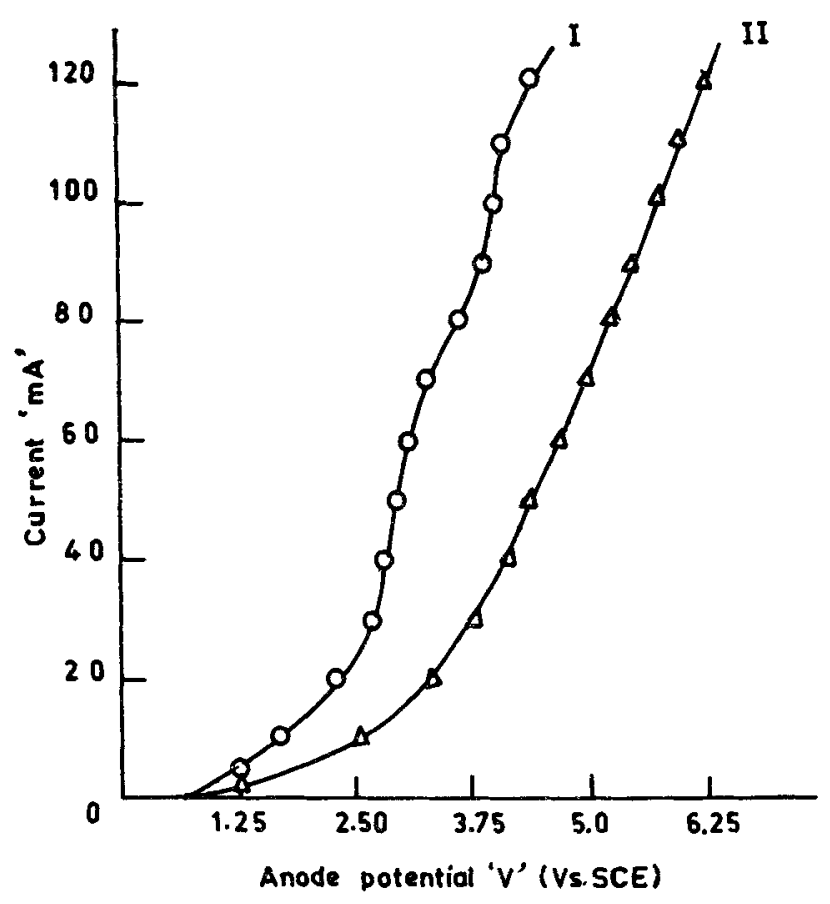

Figure 6. Anode potential vs current curve for electrochemical synthesis of polyurethane in DMF. Temperature $=30-35 \mathrm{C},\left(\mathrm{ZnCl}_{2}\right)=0.1 \mathrm{M}$. (I) without $\mathrm{MDI}+$ polyol mixture, and (II) with 2:1 molar ratio of $\mathrm{MDI}$ : polyol.

association of the isocyanate, metal ion and the alcohol. The metal ion catalysis of isocyanate hydroxyl reaction fulfilled a two-fold function: (i) it increased the electrophilic character of the carbon in the isocyanate group by coordinating either at oxygen or nitrogen and (ii) it brought both the isocyanate and alcohol in close proximity by forming a ternary complex.

Also the metal ion catalysis satisfied all the requirements of such mechanism (Robins 1965). (i) They all possessed certain complexing power so as to maintain a sufficient concentration of ternary complex, (ii) they also did not complex highly with the product thus making the removal of metal ion from the reaction mixtures unlikely.

\section{Acknowledgements}

One of the authors (PAKN) is thankful to CSIR, New Delhi for a fellowshıp.

\section{References}

Dietrich D, Bayer O and Peter J 1962 German Patent 1184946

Estes G M, Cooper S L and Tubolsky A V 1970 J. Macromol. Sci. Rev. Macromol. Chem. 4313

Funt B L, McGregor I and Tanner T 1970 J. Polym. Sci. B8 695, 699

Funt B L and Rybicky J 1971 J. Polym. Sci. A9 1441

Gaylor N G and Takahashi A 1969 Adv. Chem. Ser. 9194 
Gibson P E, Vallanee M A and Cooper S L 1982 in Developments in block copolymers I (ed.) Goodman (London: Appl. Sci. Soc., Elsevier)

Goldberg A I, Hohenstein W P and Mark H 1967 J. Polym. Sci. 2562

Kern W and Quast H 1953 Makromol. Chem. 10202

Kolthoff I M and Redly J B 1961 J. Electrochem. Soc. 108980

Noshay A and Mc Grath J E (eds) 1973 in Block copolymers (New York: Wiley)

Parravano G 1951 J. Am. Chem. Soc. 73628

Robins J 1965 J. Appl. Polym. Sci. 9821 